\title{
Effect of Auricular Acupuncture with Semi-Permanent Ear Needles on Controlling Migraine Symptoms: A Single-Blind Randomized Clinical Trial
}

\author{
Mehran Razvani Habibabadi', Fereshteh Ashtari², Iman Raeisi ${ }^{3, *}$ \\ ${ }^{1}$ Department of Anesthesiology, Anesthesiology and Critical Care Research Center, Kashani Hospital, Isfahan University of Medical \\ Sciences, Isfahan, Iran \\ ${ }^{2}$ Neurology Department, Isfahan University of Medical Sciences, Isfahan Neuroscience Research Center, Isfahan, Iran \\ ${ }^{3}$ Resident of Anesthesiology, Isfahan University of Medical Sciences, Isfahan, Iran
}

Received August 14, 2020

Revised January 13, 2021

Accepted March 8, 2021

Correspondence to Iman Raeisi

Resident of Anesthesiology, Isfahan University of Medical Sciences,

Isfahan, Iran

E-mail Imanr20@yahoo.com
Background: Migraine is a very common neurobiological headache disorder caused by an increased irritability of the central nervous system. Acupuncture as a complementary medicine has been suggested as one of the treatments for migraine headaches; however, the findings are conflicting.

Objectives: Therefore, the aim of this study was to evaluate the effect of acupuncture with auricular semi-permanent (ASP) needles on migraine headaches.

Methods: In this single-blind randomized controlled trial, 80 patients with migraine were selected and divided into two groups. The intervention group was treated with auricular ASP needles in the active points of the ear, and the control group only received routine treatments. Pain score, frequency of migraine headaches, duration of headaches, severity of nausea and vomiting, and patient satisfaction were compared between the two groups for four weeks after the intervention.

Results: Our results showed that the level of pain $(4.72 \pm 2.53,2.13 \pm 1.76$ times $)$ and the frequency of migraine headaches $(8.98 \pm 8.58$ hours $)$ from the second week after the intervention in the ASP group were much lower than those in the control group $(p<0.05)$. However, pain incidence and ear inflammation in the ASP group were negligible and did not differ significantly from those in the control group $(p>0.05)$.

Conclusion: Auricular acupuncture could be considered as a promising complementary therapy along with other standard migraine therapies for the prevention and treatment of migraine headaches.

Keywords: Migraine headache, Auricular acupuncture, Semi-permanent needle

\section{INTRODUCTION}

Migraine is a very common neurobiological headache disorder caused by an increased irritability of the central nervous system and is one of the most debilitating medical conditions. The diagnosis of migraine is based on the characteristics and symptoms of the headache [1-3]. Studies conducted in Europe and the United States (US) have shown that the prevalence of migraines is about $20 \%$ in women and $6 \%$ in men [4]. An estimated $15 \%$ of people worldwide have migraine headaches. Besides, $13 \%$ of adults in the United Kingdom (UK) have chronic headaches, and $7 \%$ of the mentioned adults are migraine patients [5]. Depression, chronic fatigue, absence from work, disability, family problems, and medication dependence are some of the psychosocial problems that migraine patients face $[1,6]$. Migraine severely restricts patients' social activities and reduces their ability to perform housework as well as physical and non-physical activities [7-9].

Different modalities such as pharmacotherapy and psychotherapy have been used to alleviate headaches. Medication treatments in pregnant women and patients with hypertension and cardiovascular disease are limited. All medications in addition to their relatively low effectiveness have a variety of long-term side effects, as a result of which many patients with migraine headaches do not currently have satisfactory prophylactic treatment for their migraine attack. Hence, a safe and cost-effective approach is required in this 
regard.

Acupuncture has been reported to be effective in the treatment of migraine headaches $[10,11]$. This method is derived from the traditional medicine in China and has been practiced by physicians for over 3,000 years. Over the years, acupuncture analgesia has attracted the attention of many specialists [12]. Some previous studies regarding the relief of migraine pain using acupuncture have presented contradictory results [13-16]. Acupuncture can be performed in different ways, one of which is auriculotherapy or auricular acupuncture. The mentioned method tries to control the disease by stimulating the ear points with different routes. One way to stimulate the ear is to use auricular semi-permanent (ASP) needles, in which a therapeutic response is elicited by continuously stimulating the ear points. Therefore, the aim of this study was to evaluate the effect of auricular ASP needles in migraine patients.

\section{MATERIALS AND METHODS}

\section{Study design and participants}

This was a single-blind randomized clinical trial. The study population consisted of all patients with migraine who were referred to a neurologist between 2019 and 2020.

The sample size in each group was considered to be approximately 40 patients based on the sample size formula, comparison of the mean of the two groups at $95 \%$ confidence level, test power of $80 \%$, and consideration of the results of previous studies [15]. The standard deviation of the number of days with migraine in the two groups with and without acupuncture treatment was calculated to be 1.7 and 2.9, respectively, with the mean variation as 1.6.

Patients eligible for participating in the study had migraine and were within the age range of $18-65$ years. These patients were diagnosed and identified based on the International Classification of Headache Disorders (ICHD-3) by a neurologist [16]. Moreover, pregnant patients, patients with severe coagulation disorders receiving anti-coagulant medications in which acupuncture may cause bleeding, patients with advanced malignancies or underlying diseases, patients with non-migraine headaches, patients with a history of drug or alcohol abuse or alcohol dependence, patients with a history of neurological or psychiatric illnesses, patients with asthma or respiratory disorders, patients using analgesics for chronic pain for more than three days a month, patients with prior auricular acupuncture, patients with severe ear abnormalities, patients with head or facial neuralgia, patients with other neurological diseases, patients with aura without headache, and patients with migraine headache diagnosed after the age of 50 years were not included in the study. Patients were also excluded from the study if they developed redness or infection at the site of the needle implant, used other analgesics during the study, or were unwilling to continue their cooperation in the present study.

To prevent the reduction in sample size following patient dropout and to encourage patients to cooperate in this study, the advantages of the present study were explained to patients, and all treatments were performed free of charge. Finally, if patients discontinued the study, they were replaced with their counterparts (Fig. 1).

\section{Randomization and blinding}

A non-probability convenience sampling technique was used to select the study sample from available eligible patients with migraine headaches who referred to the acupuncture clinic. Then, these patients were divided into two groups using random allocation software in the acupuncture clinic.

To meet the conditions of single blinding, the patient was not made aware of the type of therapeutic intervention. A piece of adhesive paper without a needle was used in the control group, and a piece of adhesive paper was placed on the ASP needles implanted in the patient's ears in the intervention group. However, due to the nature of the study, the acupuncturist could not be blinded to the nature of the therapeutic intervention. However, outcome assessors, data collectors, and statisticians were unaware of the treatment allocation.

\section{Intervention}

This research project was approved by the Ethics Committee of Isfahan University of Medical Sciences, Isfahan, Iran (Ethical code: IR.MUI.MED.REC.1397.153). In addition, it was registered in the Iranian registration system (\#IRCT2020 0213046477N1; https://irct.ir/trial/46114) before the initiation of participant recruitment.

All patients were treated with propranolol $20 \mathrm{mg}$ every 12 hours. The intervention group was provided acupuncture with ASP needles in the active points of the ears.

Twenty points were examined in the intervention group. Migraine-affected acupuncture was identified by the Pointoselect Digital point finder (Name: jiajian; Manufacturer: GENERIC; Country: China), in each ear. A maximum of four ASP needles were implanted in the most active points in each ear.

Twenty effective migraine points were specified according to reliable acupuncture references including Sympathetic [17-19], Gallbladder [17,20], GB3 (Gallbladder 3) [21], GB40 (Gallbladder 40) [20], Lesser Occipital Nerve [18,19], Thalamus [17,22], Ear Apex, Forehead [17-19, 22], Zero [17,18], Shen Men [17,18,22], PGE1 (Prostaglandin 1) [21], PGE2 (Prostaglandin 2) [21], Liver [19], Hypothalamus [18,20], Frustration [18,22], Temple [17-19], Occiput [19,22], local 


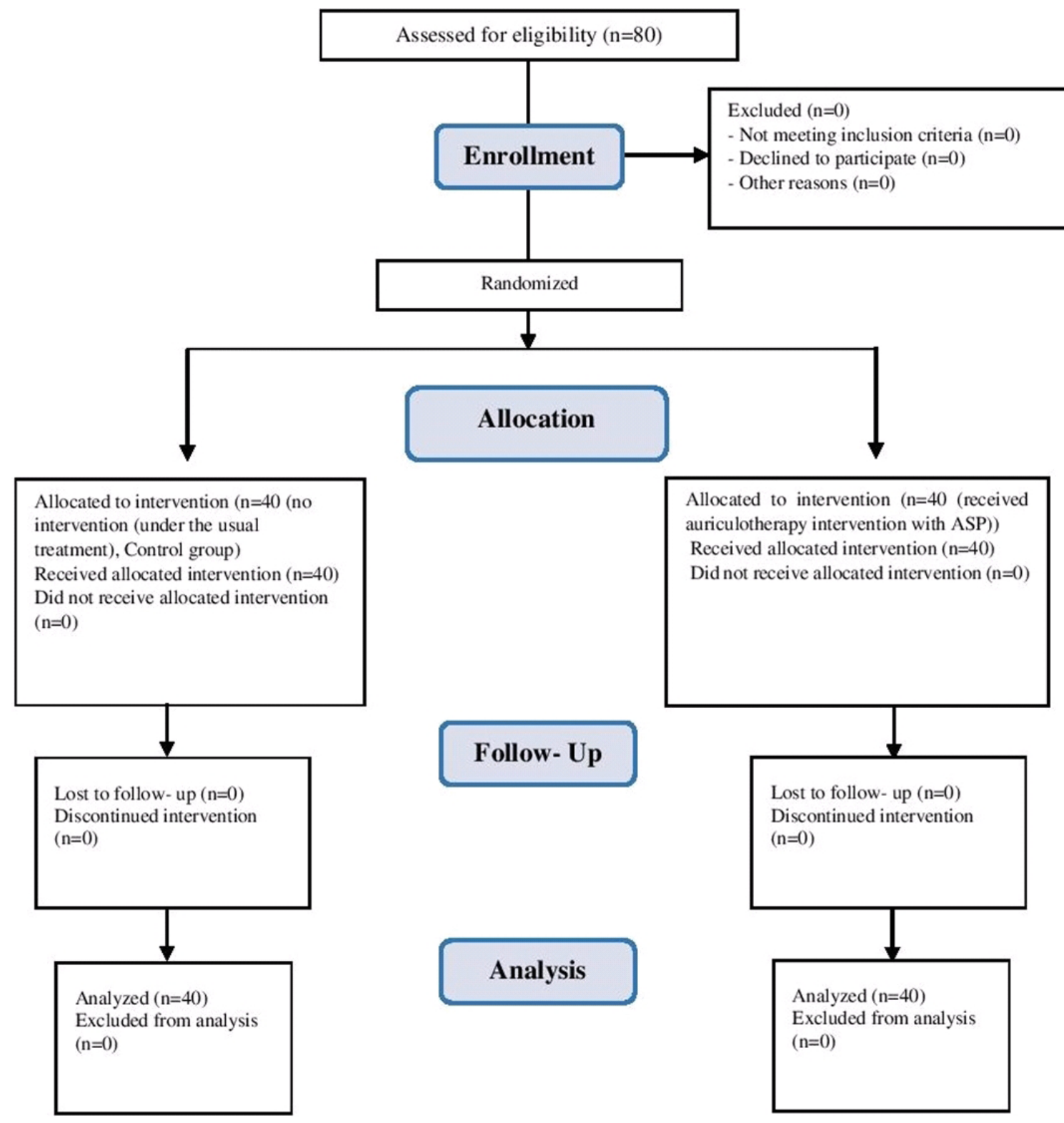

Fig. 1. The consort patient flow diagram.

cervical point (back) [20,21], local cervical point (front) [18,21], and worry point (Fig. 2) [20].

The acupuncture technique was performed by an anesthesiologist and pain medicine specialist who had an auricular medicine certificate along with 15 years of experience in this field.

In the control group, a piece of adhesive tape was placed on the inactive points of the ears. Based on the auriculotherapy maps, hands and feet play a minor role in the neurohumoral activation and nervous systems. Hence, the hands from fingers to elbows were scanned, and if they were found to be inactive by the Pointoselect Digital point finder, the adhesive tapes were used at a distance of $3 \mathrm{~mm}$ from each other. In case of identifying any active point in the hands by the device, the tape was placed at an inactive point $2 \mathrm{~mm}$ adjacent to the active point.

The mentioned technique was repeated after two weeks for both groups. Moreover, the patients were followed up every week for four weeks.

\section{Outcome measures}

At the beginning of the study, patients' demographic information including age, sex, and duration of migraine were recorded.

The number of days per week with migraine episodes, frequency of migraine headaches, and longest headache duration 


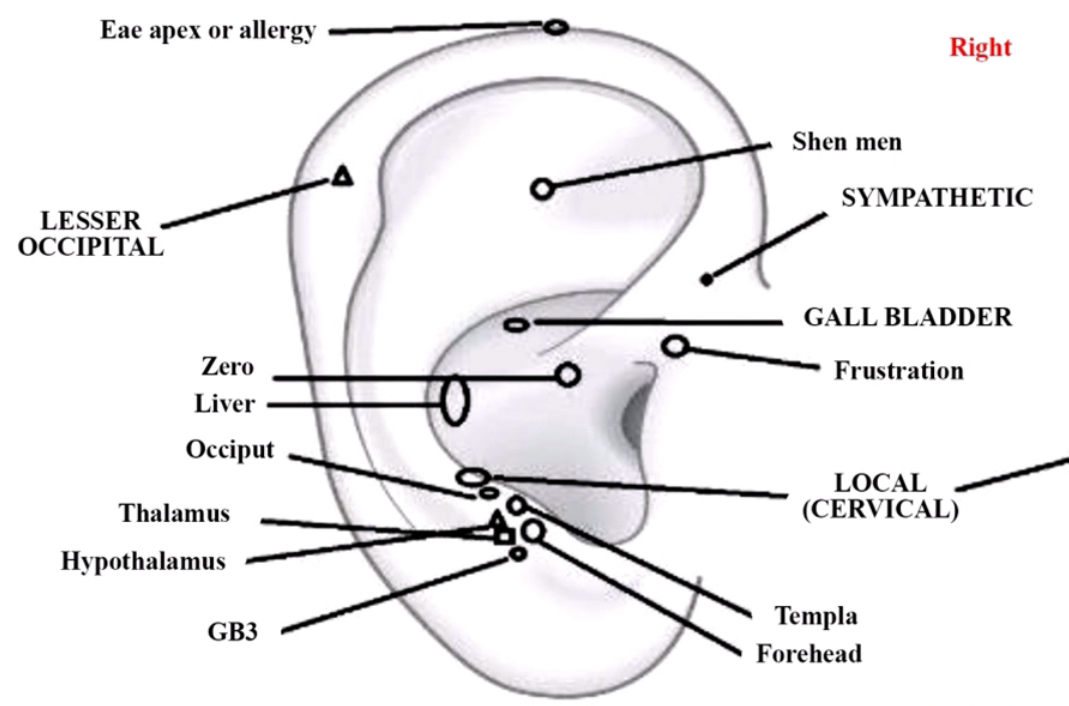

Right

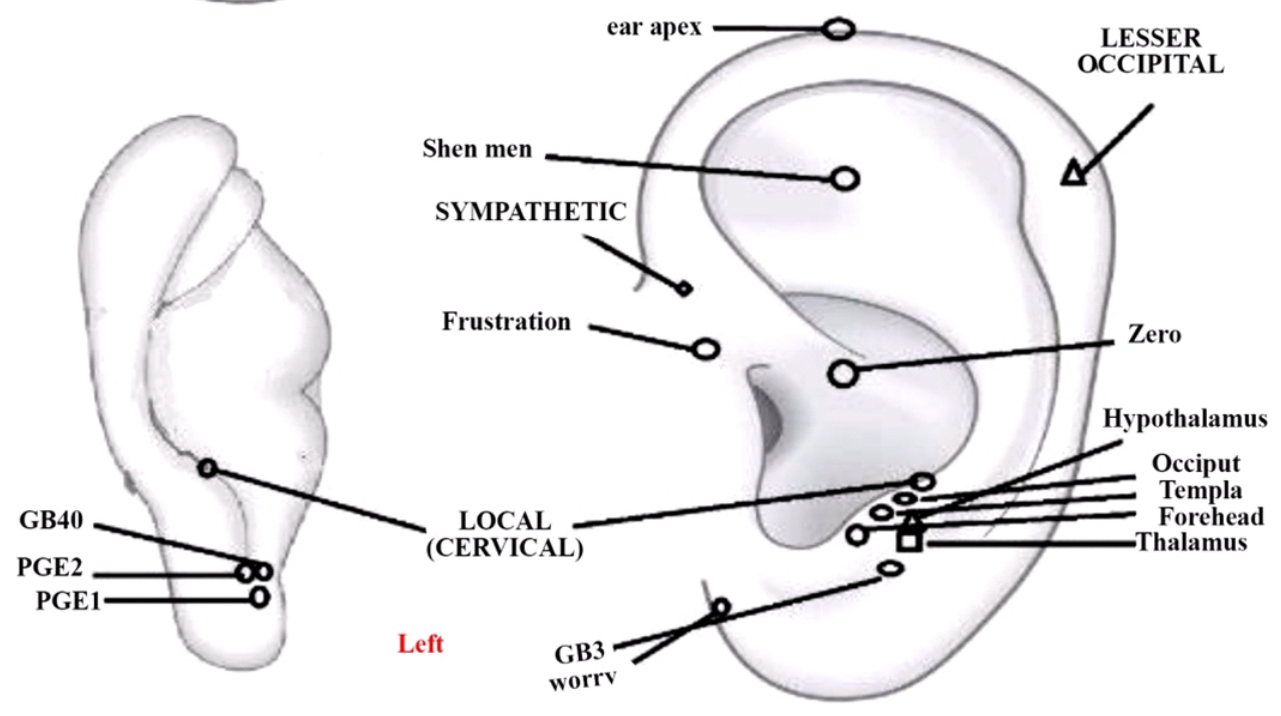

Fig. 2. Active points of acupuncture effective in migraine headache.

were considered as the primary outcome. Pain score, severity of nausea, severity of vomiting, and possible complications of ASP implantation (such as infection, ear pain, ear swelling, hematoma, and erythema) were the secondary outcomes. The primary and secondary outcomes were recorded before the study and every week after the intervention for up to four weeks.

Patients' pain was evaluated using the visual analog scale (VAS) on a scale of 0 to 10 , and the patient was asked about the most severe headache over the past week. If the patient had a VAS pain score of greater than 3, they were advised to take a Novafen capsule (acetaminophen $325 \mathrm{mg}$, caffeine 40 $\mathrm{mg}$, and ibuprofen $200 \mathrm{mg}$ ) every 8 hours.

Patients' satisfaction was assessed at the end of study using a scale of 0 (no satisfaction) to 10 (complete satisfaction).

All follow-ups of the patients' condition were either con- ducted via telephone or in the clinic as per the patients' desire.

\section{Statistical analysis}

SPSS software, Version 25 (SPSS Inc., Chicago, IL, USA) was used for statistical analysis. The obtained data are presented as the mean \pm standard deviation (SD) and frequency (percentage of frequency). At the level of inferential statistics, chi-square test was used to compare the frequency distribution of qualitative data between the two groups. According to the result of Kolmogorov-Smirnov test indicating the normal distribution of data, chi-square test, independent samples $t$-test, repeated-measures ANOVA, and univariate analysis by adjusting for sex, age, and use of Novafen were used. The significance level was considered as less than 0.05 in all analyses. 


\section{RESULTS}

In the present study, out of 40 patients in the ASP group with a mean age of $37.1 \pm 9.33$ years, 8 patients $(20 \%)$ and 32 patients (80\%) were male and female, respectively. The control group with a mean age of $36.65 \pm 8.86$ years included 9 male patients (22.5\%) and 31 female patients $(77.5 \%)(p>0.05)$ (Table 1).

There was no significant difference between the two groups

Table 1. Basic characteristics of patients in two groups

\begin{tabular}{lrcc}
\hline \multicolumn{1}{c}{ Characteristics } & $\begin{array}{c}\text { ASP group } \\
(\mathrm{n}=40)\end{array}$ & $\begin{array}{c}\text { Control group } \\
(\mathrm{n}=40)\end{array}$ & $p$ \\
\hline Sex & & & 0.802 \\
$\quad$ Male & $8(20 \%)$ & $9(22.5 \%)$ & \\
$\quad$ Female & $32(80 \%)$ & $31(77.5 \%)$ & \\
Age, years & $37.1 \pm 9.33$ & $36.65 \pm 8.86$ & 0.826 \\
$\begin{array}{l}\text { Duration of migraine } \\
\text { illness, years }\end{array}$ & $10.74 \pm 8.02$ & $10.50 \pm 6.61$ & 0.883 \\
\hline
\end{tabular}

$\mathrm{ASP}=$ auricular semi-permanent.

Table 2. Determination and comparison of the mean primary outcome of migraine between the two groups over four weeks

\begin{tabular}{|c|c|c|c|}
\hline Variable & $\begin{array}{l}\text { ASP group } \\
(\mathrm{n}=40)\end{array}$ & $\begin{array}{l}\text { Control group } \\
\qquad(\mathrm{n}=40)\end{array}$ & ${ }^{*} p$ \\
\hline \multicolumn{4}{|l|}{$\begin{array}{l}\text { Number of days per } \\
\text { week with migraine }\end{array}$} \\
\hline Baseline & $3.37 \pm 1.25$ & $3.25 \pm 1.06$ & 0.631 \\
\hline \multicolumn{4}{|l|}{ After treatment } \\
\hline First week & $2.50 \pm 0.82$ & $2.77 \pm 0.73$ & 0.117 \\
\hline Second week & $2.47 \pm 0.93$ & $2.35 \pm 0.83$ & 0.529 \\
\hline Third week & $1.72 \pm 0.64$ & $2.17 \pm 0.75$ & 0.005 \\
\hline Fourth week & $1.23 \pm 0.77$ & $1.75 \pm 0.59$ & 0.001 \\
\hline \multicolumn{4}{|c|}{$\begin{array}{l}\text { Frequency of migraine } \\
\text { headaches }\end{array}$} \\
\hline Baseline & $3.72 \pm 2.19$ & $4.00 \pm 2.49$ & 0.602 \\
\hline \multicolumn{4}{|l|}{ After treatment } \\
\hline First week & $2.69 \pm 2.28$ & $3.36 \pm 2.09$ & 0.201 \\
\hline Second week & $2.13 \pm 1.76$ & $3.54 \pm 2.19$ & 0.003 \\
\hline Third week & $2.40 \pm 1.94$ & $3.81 \pm 1.38$ & 0.008 \\
\hline Fourth week & $2.39 \pm 2.06$ & $3.92 \pm 2.26$ & 0.005 \\
\hline \multicolumn{4}{|l|}{$\begin{array}{l}\text { Longest headache } \\
\text { duration }\end{array}$} \\
\hline Baseline & $19.59 \pm 18.17$ & $19.15 \pm 17.46$ & 0.913 \\
\hline \multicolumn{4}{|l|}{ After treatment } \\
\hline First week & $8.22 \pm 9.41$ & $16.76 \pm 14.78$ & 0.004 \\
\hline Second week & $8.98 \pm 8.58$ & $19.87 \pm 17.13$ & 0.001 \\
\hline Third week & $6.54 \pm 7.75$ & $18.56 \pm 17.20$ & $<0.001$ \\
\hline Fourth week & $5.19 \pm 7.06$ & $19.81 \pm 16.99$ & $<0.001$ \\
\hline
\end{tabular}

Data are shown as the mean \pm SD.

* $p$ obtained from the univariate analysis by adjusting for sex, age, and use of Novafen (acetaminophen/caffeine/ibuprofen).

ASP $=$ auricular semi-permanent. in terms of the number of days per week with migraine, the frequency of migraine headaches, and the longest duration of headache before the intervention $(p>0.05)$. However, the number of days per week with migraine from the third week, the frequency of migraine headaches from the second week, and the longest duration of headache from the first week after intervention in the ASP group were significantly lower than those in the control group $(p<0.001)$ (Table 2).

As secondary outcomes, the severity of nausea and vomiting was not significantly different between the two groups at any of the follow-up times $(p>0.05)$, but the pain score from the second week after intervention in the ASP group was significantly lower than that in the control group $(p<0.001)$ (Table 3). In addition, repeated-measures ANOVA revealed a significant decrease and increase in migraine pain level and symptoms observed over time in the ASP and control groups, respectively $(p<0.05)$.

Examination of the incidence of complications also revealed that erythema, hematoma, and ear infection did not occur. The incidence percentage of ear swelling in the ASP group was not significantly different from that in the control group (without ear swelling) $(p>0.05)$. Although the frequency of ear pain in the ASP group in the second and third weeks was

Table 3. Determination and comparison of the mean secondary outcome of migraine between the two groups over four weeks

\begin{tabular}{lccc}
\hline \multicolumn{1}{c}{ Variable } & $\begin{array}{c}\text { ASP group } \\
(\mathrm{n}=40)\end{array}$ & $\begin{array}{c}\text { Control group } \\
(\mathrm{n}=40)\end{array}$ & ${ }^{*} p$ \\
\hline $\begin{array}{c}\text { Pain score } \\
\text { Baseline }\end{array}$ & $7.60 \pm 1.81$ & $7.52 \pm 2.11$ & 0.865 \\
After treatment & & & \\
$\quad$ First week & $5.16 \pm 3.26$ & $5.86 \pm 2.46$ & 0.294 \\
$\quad$ Second week & $4.72 \pm 2.53$ & $5.97 \pm 2.68$ & 0.038 \\
$\quad$ Third week & $4.55 \pm 2.49$ & $6.32 \pm 2.55$ & 0.003 \\
$\quad$ Fourth week & $3.82 \pm 2.68$ & $6.60 \pm 2.59$ & $<0.001$ \\
Severity of nausea & & & \\
Baseline & $5.25 \pm 2.27$ & $5.07 \pm 1.92$ & 0.746 \\
After treatment & & & \\
$\quad$ First week & $3.70 \pm 2.99$ & $3.88 \pm 2.63$ & 0.825 \\
$\quad$ Second week & $2.20 \pm 2.21$ & $3.21 \pm 2.68$ & 0.210 \\
$\quad$ Third week & $2.50 \pm 2.46$ & $3.67 \pm 2.87$ & 0.248 \\
$\quad$ Fourth week & $2.00 \pm 2.69$ & $3.44 \pm 2.75$ & 0.179 \\
Severity of vomiting & & & \\
Baseline & $0.45 \pm 0.93$ & $0.50 \pm 1.01$ & 0.819 \\
After treatment & & & \\
$\quad$ First week & $0.10 \pm 0.65$ & $0.05 \pm 0.22$ & 0.156 \\
Second week & - & $0.18 \pm 0.45$ & - \\
Third week & - & $0.15 \pm 0.36$ & - \\
Fourth week & - & $0.10 \pm 0.30$ & - \\
\hline
\end{tabular}

Data are shown as means \pm SD.

* $p$ obtained from the univariate analysis by adjusting for sex, age, and the use of Novafen (Acetaminophen/Caffein/lbuprofen).

ASP $=$ auricular semi-permanent. 
Table 4. Comparison of the frequency distribution of complications between the two groups

\begin{tabular}{cllc}
\hline Complication & $\begin{array}{c}\text { ASP group } \\
(\mathrm{n}=40)\end{array}$ & $\begin{array}{c}\text { Control } \\
\text { group } \\
(\mathrm{n}=40)\end{array}$ & ${ }^{*} p$ \\
\hline $\begin{array}{c}\text { Ear swelling } \\
\text { Baseline }\end{array}$ & $0(0 \%)$ & $0(0 \%)$ & - \\
After treatment & & & \\
$\quad$ First week & $4(10 \%)$ & $0(0 \%)$ & 0.116 \\
$\quad$ Second week & $1(2.5 \%)$ & $0(0 \%)$ & 0.999 \\
Third week & $4(10 \%)$ & $0(0 \%)$ & 0.116 \\
$\quad$ Fourth week & $2(5 \%)$ & $0(0 \%)$ & 0.494 \\
Ear pain & & & \\
Baseline & $0(0 \%)$ & $0(0 \%)$ & - \\
After treatment & & & \\
$\quad$ First week & $3(7.5 \%)$ & $0(0 \%)$ & 0.210 \\
Second week & $7(17.5 \%)$ & $0(0 \%)$ & 0.022 \\
Third week & $6(15 \%)$ & $0(0 \%)$ & 0.039 \\
$\quad$ Fourth week & $2(5 \%)$ & $0(0 \%)$ & 0.494 \\
\hline
\end{tabular}

${ }^{*} p$ obtained from chi-square test.

ASP $=$ auricular semi-permanent.

significantly higher than that in the control group (without ear pain), the mentioned ear pain was significantly reduced in the fourth week such that there was no significant difference between the two groups $(p=0.49)$ (Table 4 ).

Finally, the level of patients' satisfaction with improvement of migraine symptoms in the ASP group with the mean of $7.10 \pm$ 2.69 was significantly higher than that in the control group with the mean of $3.10 \pm 2.75(p<0.001)$.

\section{DISCUSSION}

In this investigation, although the severity of migraine headache as well as the number of episodes after the intervention did not decrease significantly in the first week, they were significantly reduced in the ASP group as compared to the control group in the follow-ups. Acupuncture also significantly reduced the duration of patients' headaches. However, there was a significant decrease in the amount of analgesic use in patients, and there was a slight decrease in the analgesic use in the first three weeks after the acupuncture. This highlights the efficacy of acupuncture in the intervention group. No serious complications following the acupuncture were reported in this study, and all patients with reported complications eventually recovered with treatment recommendations.

The most important mechanisms for placebo effects include expectations of recovery, conditioning, anxiety reduction, and social support $[17,18]$. Many placebo sham acupuncture procedures include placing needle in locations that are not traditional points with the same frequency and duration as it was the case in the real acupuncture group. In some studies, needles have been inserted into the classical acupuncture points not specific to migraine. Most of the physiological mechanisms implied that acupuncture does not necessarily exhibit a point property [19]. Even non-penetrating "placebo" needles may activate unmyelinated afferent nerves (C tactile) that can affect pain perception [20]. Some of the effects of acupuncture may not be specific to a particular point [21,22], and these are particularly important for the treatment of conditions other than local pain $[23,24]$. As a result, a reduction in pain in the placebo group is expected especially at the beginning of the intervention.

The founder of modern auricular acupuncture is Paul Nogier [25-27], a general practitioner in France, who developed an ear map [26]. The efficacy of auricular acupuncture and somatic acupuncture in controlling pain is well known [25,28-32]; however, the analgesic mechanism of auricular acupuncture is still unidentified.

Neuronal mechanisms related to the ear innervation, which comprises the auricular branch of the vagus nerve, the auriculotemporal branch of the trigeminal nerve, the great auricular nerve from the second and third cervical roots as well as the facial and glossopharyngeal nerve might have a role in migraine headaches [33]. In Western medicine, the trigeminovascular pathway has been implicated in migraine headaches [34]. The suggested cause of vestibular migraine symptoms involves neurological inflammation through activation of the trigeminal-vestibulocochlear reflex [35]. The trigeminal nerve may be responsible for the effects of auricular acupuncture on the treatment of migraine headaches. The trigeminal pain modulation input structures including rostral ventromedial medulla, ventrolateral periaqueductal gray, locus coeruleus, and the nucleus raphe magnus are all affected by acupuncture [35-40].

In addition, there are neurovascular complexes in the ear including the nerve fibers, capillaries, and lymphatics. These sites are suggested to be stimulated by acupuncture [41]. Cholinergic and adrenergic fibers are also present in the ear and may be the primary cause of neurotransmitter release. Acupuncture has also been shown and approved by functional MRI to stimulate the cortical and limbic areas of the pain pathway in the central nervous system [31].

In a review study by Griggs and Jensen [5], it has been indicated that over the past 20 years a large fraction of trials addressing the effects of acupuncture on migraine headaches were of poor quality with contradictory results. Therefore, the authors recommend performing more high-quality studies, which has also been suggested in other review studies [42]. In some countries such as Germany, the therapeutic effects of acupuncture on headache and migraine have been well studied [43]. Allais et al. [30] used the needle-to-ear contact 
test for the acute unilateral migraine attack and showed that $64.5 \%$ of patients experienced a significant remission in the first 24 hours [30].

Furthermore, Plank et al.'s [44] study revealed that acupuncture significantly reduces the frequency and severity of migraine pain. Valid survey measures used to assess the effect of migraine on the quality of life indicated a statistically significant improvement after the intervention as compared to baseline.

Ceccherelli et al. [45] compared the clinical efficacy of somatic and auricular acupuncture in the treatment of migraine without aura and found that pain at the end of the treatment was significantly lower than that before the treatment such that residual pain levels in somatic and ear acupuncture were $54.81 \%$ and $43.63 \%$, respectively. The two treatments appeared to be equally effective. These results, although preliminary, are very promising to support the effectiveness of auricular acupuncture for the treatment of migraine without aura.

Although the sample size of this study was small, the lack of patient dropout, encouragement of patients to cooperate in the follow-ups until the end of the treatment, and patients' high satisfaction can be regarded as the strengths of this study. In addition, the feature distinguishing this study from other studies was the use of urological complementary medicine and the selection of active points with the point selector device and the use of ASP needles with gold and silver plating. Although the presentation of patients' pain level was based on their self-report, it was shown that patients' pain along with other migraine symptoms in the intervention group improved more than those in the control group. Therefore, the promising findings of this study lay the foundation for similar studies with a larger sample size.

\section{CONCLUSIONS}

According to the results of the present study, the level of pain and the frequency of migraine headaches from the second week after intervention in the ASP group were much lower than those in the control group, even though migraine symptoms improved in both groups. Moreover, pain incidence and ear inflammation in the ASP group were negligible and did not differ significantly from those in the control group. In addition, the level of patient satisfaction in the ASP group was much higher than that in the control group. Therefore, it seems that acupuncture with ASP needles can be considered as a complementary medicine along with the usual treatment for migraine.

\section{AUTHORS' CONTRIBUTIONS}

M. Razvani-Habibabadi performed the ear acupuncture for patients and contributed to the approval of the final version of the manuscript. I. Raeisi contributed to the design of the study, the definition of the intellectual content of the work, the follow-up of the patients, and the writing of the article. F. Ashtari contributed to the conceptualization of the study, literature search, and clinical study. All the authors listed above contributed equally in preparing the manuscript.

\section{CONFLICT OF INTEREST}

The authors declare no conflict of interest.

\section{ORCID}

Mehran Razvani Habibabadi, https://orcid.org/0000-0002-9047-4378

\section{REFERENCES}

1. Gilmore B, Michael M. Treatment of acute migraine headache. Am Fam Physician 2011;83:271-80.

2. Spector JT, Kahn SR, Jones MR, Jayakumar M, Dalal D, Nazarian S. Migraine headache and ischemic stroke risk: an updated meta-analysis. Am J Med 2010;123:612-24.

3. Freitag FG. The cycle of migraine: patients' quality of life during and between migraine attacks. Clin Ther 2007;29:93949.

4. Garza I, Schwedt TJ, Robertson CE, Smith JH. Headache and other craniofacial pain. In: Jankovic J, Mazziotta JC, Pomeroy SL, eds. Bradley's Neurology in Clinical Practice, 7th ed. Philadelphia: Elsevier, 2016:1686-719.

5. Griggs C, Jensen J. Effectiveness of acupuncture for migraine: critical literature review. J Adv Nurs 2006;54:491-501.

6. Blumenfeld A. Clinical approaches to migraine prophylaxis. Am J Manag Care 2005;11(2 Suppl):S55-61.

7. Lantéri-Minet M, Duru G, Mudge M, Cottrell S. Quality of life impairment, disability and economic burden associated with chronic daily headache, focusing on chronic migraine with or without medication overuse: a systematic review. Cephalalgia 2011;31:837-50.

8. Bicakci S, Over F, Aslan K, Bozdemir N, Saatci E, Sarica Y. Headache characteristics in senior medical students in Turkey. Tohoku J Exp Med 2007;213:277-82.

9. Bigal ME, Lipton RB. The differential diagnosis of chronic daily headaches: an algorithm-based approach. J Headache Pain 2007;8:263-72.

10. Lipton RB, Bigal ME, Rush SR, Yenkosky JP, Liberman JN, Bartleson JD, et al. Migraine practice patterns among neuro- 
logists. Neurology 2004;62:1926-31.

11. Li YX, Xiao XL, Zhong DL, Luo LJ, Yang H, Zhou J, et al. Effectiveness and safety of acupuncture for migraine: an overview of systematic reviews. Pain Res Manag 2020;2020:3825617.

12. Adams J, Barbery G, Lui CW. Complementary and alternative medicine use for headache and migraine: a critical review of the literature. Headache 2013;53:459-73.

13. Facco E, Liguori A, Petti F, Zanette G, Coluzzi F, De Nardin $\mathrm{M}$, et al. Traditional acupuncture in migraine: a controlled, randomized study. Headache 2008;48:398-407.

14. Vickers AJ, Cronin AM, Maschino AC, Lewith G, MacPherson H, Foster NE, et al.; Acupuncture Trialists' Collaboration. Acupuncture for chronic pain: individual patient data metaanalysis. Arch Intern Med 2012;172:1444-53.

15. Mauskop A. Nonmedication, alternative, and complementary treatments for migraine. Continuum (Minneap Minn) 2012;18: 796-806.

16. Allais G, De Lorenzo C, Quirico PE, Airola G, Tolardo G, Mana $\mathrm{O}$, et al. Acupuncture in the prophylactic treatment of migraine without aura: a comparison with flunarizine. Headache 2002; 42:855-61.

17. Crow R, Gage H, Hampson S, Hart J, Kimber A, Thomas H. The role of expectancies in the placebo effect and their use in the delivery of health care: a systematic review. Health Technol Assess 1999;3:1-96.

18. Benedetti F. Mechanisms of placebo and placebo-related effects across diseases and treatments. Annu Rev Pharmacol Toxicol 2008;48:33-60.

19. Bäcker M, Gareus IK, Knoblauch NT, Michalsen A, Dobos GJ. [Acupuncture in the treatment of pain--hypothesis to adaptive effects]. Forsch Komplementarmed Klass Naturheilkd 2004;11: 335-45. German.

20. Lund I, Lundeberg T. Are minimal, superficial or sham acupuncture procedures acceptable as inert placebo controls? Acupunct Med 2006;24:13-5.

21. Han JS. Physiology of acupuncture: review of thirty years of research. J Altern Complement Med 1997;3(Suppl 1):s-101-8.

22. Lundeberg T, Lund I, Näslund J. Acupuncture-self-appraisal and the reward system. Acupunct Med 2007;25:87-99.

23. Thomas M, Lundeberg T. Does acupuncture work? Pain Clin Updates 1996;4:1-4.

24. Borud E, Grimsgaard S, White A. Menopausal problems and acupuncture. Auton Neurosci 2010;157:57-62.

25. Goertz CM, Niemtzow R, Burns SM, Fritts MJ, Crawford CC, Jonas WB. Auricular acupuncture in the treatment of acute pain syndromes: a pilot study. Mil Med 2006;171:1010-4.

26. Nogier R. How did Paul Nogier establish the map of the ear? Med Acupunct 2014;26:76-83.

27. Zhang SP, Chung WY, Zhan YJ. Auricular acupuncture for pain and inflammation. In: Xia Y, Ding G, Wu GC, eds. Current Research in Acupuncture. New York: Springer, 2013:517-31.
28. Lin Y, Aimee B, Lee A. Acupuncture for the management of pediatric pain: a pilot study. Med Acupunct 2003;14:45-6.

29. Allais G, Romoli M, Rolando S, Airola G, Castagnoli Gabellari I, Allais R, et al. Ear acupuncture in the treatment of migraine attacks: a randomized trial on the efficacy of appropriate versus inappropriate acupoints. Neurol Sci 2011;32 Suppl 1: S173-5.

30. Allais G, Romoli M, Rolando S, Castagnoli Gabellari I, Benedetto C. Ear acupuncture in unilateral migraine pain. Neurol Sci 2010;31 Suppl 1:S185-7.

31. Romoli M, Allais G, Airola G, Benedetto C. Ear acupuncture in the control of migraine pain: selecting the right acupoints by the "needle-contact test". Neurol Sci 2005;26 Suppl 2:s158-61.

32. Vincent CA. A controlled trial of the treatment of migraine by acupuncture. Clin J Pain 1989;5:305-12.

33. Rabischong P, Terral C. Scientific basis of auriculotherapy: state of the art. Med Acupunct 2014;26:84-96.

34. Noseda R, Burstein R. Migraine pathophysiology: anatomy of the trigeminovascular pathway and associated neurological symptoms, cortical spreading depression, sensitization, and modulation of pain. Pain 2013;154 Suppl 1:S44-53.

35. Espinosa-Sanchez JM, Lopez-Escamez JA. New insights into pathophysiology of vestibular migraine. Front Neurol 2015; $6: 12$.

36. Biella G, Sotgiu ML, Pellegata G, Paulesu E, Castiglioni I, Fazio F. Acupuncture produces central activations in pain regions. Neuroimage 2001;14(1 Pt 1):60-6.

37. Chen JR, Li GL, Zhang GF, Huang Y, Wang SX, Lu N. Brain areas involved in acupuncture needling sensation of de qi: a single-photon emission computed tomography (SPECT) study. Acupunct Med 2012;30:316-23.

38. Dhond RP, Kettner N, Napadow V. Neuroimaging acupuncture effects in the human brain. J Altern Complement Med 2007;13: 603-16.

39. Liu WC, Feldman SC, Cook DB, Hung DL, Xu T, Kalnin AJ, et al. fMRI study of acupuncture-induced periaqueductal gray activity in humans. Neuroreport 2004;15:1937-40.

40. Takeshige C, Sato T, Mera T, Hisamitsu T, Fang J. Descending pain inhibitory system involved in acupuncture analgesia. Brain Res Bull 1992;29:617-34.

41. Shang C. Prospective tests on biological models of acupuncture. Evid Based Complement Alternat Med 2009;6:31-9.

42. Bender JL, Radhakrishnan A, Diorio C, Englesakis M, Jadad AR. Can pain be managed through the Internet? A systematic review of randomized controlled trials. Pain 2011;152:1740-50.

43. Molsberger AF, Boewing G, Diener HC, Endres HG, Kraehmer $\mathrm{N}$, Kronfeld K, et al. Designing an acupuncture study: the nationwide, randomized, controlled, German acupuncture trials on migraine and tension-type headache. J Altern Complement Med 2006;12:237-45.

44. Plank S, Goodard JL, Pasierb L, Simunich TJ, Croner JR. 
Standardized set-point acupuncture for migraines. Altern Ther Health Med 2013;19:32-7.

45. Ceccherelli F, Lovato A, Piana E, Gagliardi G, Roveri A. Somatic acupuncture versus ear acupuncture in migraine therapy: a randomized, controlled, blind study. Acupunct Electrother Res 2012;37:277-93. 